\title{
Crossing vessels with suspension versus transposition in laparoscopic pyeloplasty of patients with ureteropelvic junction obstruction: a retrospective study
}

\author{
Jun Liu ${ }^{1,2+}$, Jingjun Zhang ${ }^{3 \dagger}$, Weinan Chen ${ }^{1,2}$, Liulin Xiong ${ }^{1,2}$, Xiaobo Huang ${ }^{1,2}$ and Xiongjun Ye ${ }^{1,2^{*}}$
}

\begin{abstract}
Purpose: To compare the effects of two different methods of laparoscopic pyeloplasty for the treatment of crossing vessels.

Methods: From January 2016 to August 2019, 33 patients with ureteropelvic junction obstruction (UPJO) underwent laparoscopic pyeloplasty at our center, including 21 men and 12 women, ranging from 14 to 66 years of age. There were 20 and 13 cases on the left and right sides, respectively. Patients underwent laparoscopic pyeloplasty (AndersonHynes operation). During the operation, either a Hem-o-lok clip suspension or transposition was used to treat the crossing vessels. The double-J stent was removed 8 weeks after the operation. The clinical data of patients were collected and follow-ups were regularly performed after the operation.
\end{abstract}

Results: All the crossing vessels were successfully preserved, and none of them were severed during the operation. The average operation time was $210.6 \pm 58.9 \mathrm{~min}$ in this group and the average time to manage the crossing vessel was $8.0 \pm 3.5 \mathrm{~min}, 5.9 \pm 1.4 \mathrm{~min}$ in the suspension group, and $11.7 \pm 3.0 \mathrm{~min}$ in the transposition group. The dilation of the affected side was $4.8 \pm 1.5 \mathrm{~cm}$ before operation and $1.2 \pm 1.3 \mathrm{~cm} 3$ months after operation. The difference was statistically significant $(P<0.05)$. Follow-up to February 2020 showed no significant changes in the kidney size in all patients and hydronephrosis was relieved.

Conclusion: For UPJO patients with crossing vessel compression, the method of Hem-o-lok suspension or vascular transposition can be used to relieve crossing vascular compression and improve the success of pyeloplasty.

Keywords: Laparoscopic pyeloplasty, Crossing vessel, Ureteropelvic junction obstruction, Hydronephrosis

\section{Introduction}

Ureteropelvic junction obstruction (UPJO) is a common cause of hydronephrosis and renal dysfunction. There are several causes of UPJO, such as intraureteral stenosis,

\footnotetext{
*Correspondence: yexiongjun@bjmu.edu.cn

†Jun Liu and Jingjun Zhang contributed equally to this work

${ }^{1}$ Urology and Lithotripsy Center, Peking University People's Hospital,

Peking University, 133 Fuchengmen Inner Street, Xicheng District,

Beijing 100034, People's Republic of China

Full list of author information is available at the end of the article
}

ureteral dynamic dysfunction, and ectopic vascular compression. Among them, UPJO caused by crossing vessel compression accounts for $10-28.1 \%$ of adult primary UPJO [1, 2]. Ectopic renal artery, also known as crossing vessels, refers to an extra artery of the kidney, usually entering the kidney without the renal hilum, and often is accompanied by veins. Crossing vessels usually enter the lower pole of the kidney through the ventral side of the ureteropelvic junction, where mechanical compression or traction occurs, resulting in obstruction and deformation

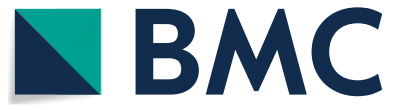

(c) The Author(s) 2021. This article is licensed under a Creative Commons Attribution 4.0 International License, which permits use, sharing, adaptation, distribution and reproduction in any medium or format, as long as you give appropriate credit to the original author(s) and the source, provide a link to the Creative Commons licence, and indicate if changes were made. The images or other third party material in this article are included in the article's Creative Commons licence, unless indicated otherwise in a credit line to the material. If material is not included in the article's Creative Commons licence and your intended use is not permitted by statutory regulation or exceeds the permitted use, you will need to obtain permission directly from the copyright holder. To view a copy of this licence, visit http://creativecommons.org/licenses/by/4.0/. The Creative Commons Public Domain Dedication waiver (http://creativecommons.org/publicdomain/zero/1.0/) applies to the data made available in this article, unless otherwise stated in a credit line to the data. 
of the local ureter, poor drainage of urine, and hydronephrosis [3]. The treatment of crossing vessels has always been controversial in clinical practice $[4,5]$ as these vessels can provide a part of the blood supply to the kidney; complete disconnection of the crossing vessels will cause loss of part of the renal function. Therefore, preserving the crossing vessels would mean protecting the integrity of the renal function. Several methods can be used to treat UPJO, including open pyeloplasty (OP), endoscopic pyelotomy (EP), laparoscopy (LP) and robot assisted pyeloplasty (RP). The success rate of RP is the highest, the complication of LP is lower than that of OP, the success rate of EP is relatively low, but the operation time is the shortest of all surgical methods [6]. In clinical work, the management of crossing vessels has always been a difficult challenge in laparoscopic pyeloplasty (LP).

From January 2016 to August 2019, 33 cases of UPJO with crossing vessel compression operated at Peking University People's Hospital were retrospectively analyzed to explore the treatment of crossing vessels in the LP.

\section{Data and methods}

\section{General clinical data}

From January 2016 to August 2019, 147 LP cases were completed in our hospital, including 33 cases (21 men; 12 women) of UPJO with ectopic renal vascular compression. All cases were selected continuously at the same time period. There were no patients with second pyeloplasty. The robot platform was not available and the OP was not performed. The average age was 32 years, ranging from to $14-66$ years of age. There were 20 and 13 cases on the left and right sides, respectively. None of the patients had a history of ureter or kidney operation. The main symptoms were hypochondriac pain, increased $\mathrm{RBC}$ count in urine, and urinary tract infection. All patients were diagnosed with UPJO by abdominal ultrasound, CT tomography urography (CTU) and/or diuretic renal dynamic imaging before surgery. The indication of operation was based on clinical symptoms (such as recurrent hypochondriac pain and urinary tract infection), imaging examination results, and obvious obstruction of diuretic renal dynamic imaging [7]. The degree of hydronephrosis was classified based on the ultrasonographic grading of hydrophysis [8]. According to the legislation of the ethics committee, we obtained the moral declaration from the ethics committee and all patients signed the preoperative informed consent.

\section{Operation method}

General anesthesia was administered in all patients in the $70^{\circ}$ lateral decubitus position. The skin was incised approximately at $2 \mathrm{~cm}$ from the umbilicus of the affected side, and pneumo-peritoneum was established by puncture using the Veress needle. Additionally, trocar $(10 \mathrm{~mm}$ in the left hand and $12 \mathrm{~mm}$ in the right hand) was placed under the costal margin of the middle clavicle and the anterior superior iliac spine. When the affected side was on the right, a $5 \mathrm{~mm}$ trocar was placed under the xiphoid process to lift the liver.

The process began with the opening of the lateral peritoneum on the lateral side of the colon and the colon was pushed to the inner and lower parts. When lifting the dilated anterior wall of the renal pelvis, the energetic knife was carefully used to dissect and fully expose the anterior and posterior walls of the renal pelvis and the upper ureter. The crossing vessels on the ventral side of the dilated renal pelvis must be found and carefully dissociated to prevent damage to the crossing vessels.

Generally, according to the location and direction of the crossing vessels, the following two surgical methods are used. (1) Suspension with Hem-o-lok clips (Weck Surgical Instruments, Research Triangle Park, NC, USA) (21 cases in suspension group, Fig. 1): When the crossing vessel is close to the hilum (above the level of the

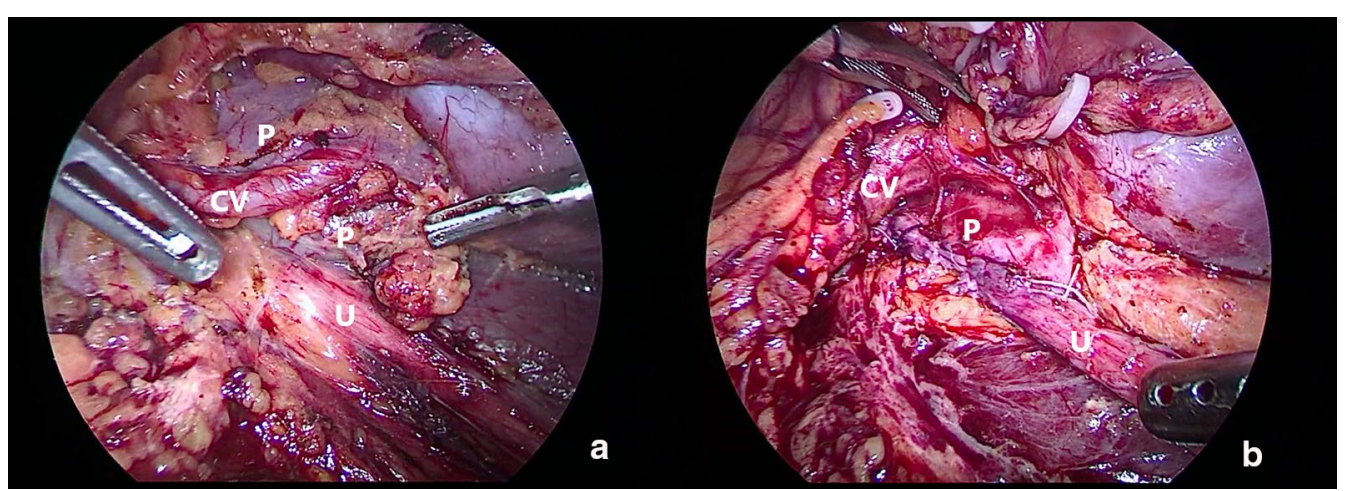

Fig. 1 Crossing vessel suspension, a before $L P, \mathbf{b}$ after $L P$ 
midline of the lower pole of the kidney) and in a tortuous shape, 2-3 Hem-o-lok clips can be used to clamp the fibrous connective tissue on the surface of the crossing vessel and then fix it on the perirenal fat sac above the hilum. Subsequently, the ureteropelvic junction (UPJ) could be exposed clear manner. Attention must be paid not to damage the crossing vessel during clamping. (2) Transposition of the crossing vessel (12 cases in transposition group, Fig. 2): When the crossing vessel is at the level of the lower pole of the kidney (below the level of the middle line of the lower pole of the kidney), transposition of the crossing vessel is feasible due to the lower position and the greater tension of the crossing vessel. First, the inferior pole of the kidney is exposed with an energetic knife, the lower pole of the kidney is picked up, and the crossing vessels are carefully dissociated, in order to be completely separated from the UPJ. After the ureteropelvic junction was dismembered, the crossing vessel was transferred to the dorsal side of the anastomosis and fixed on the fascia of the psoas major muscle above the anastomosis with suture to prevent the compression from forming again.

Subsequently, the, conventional dismembered laparoscopic pyeloplasty was performed, the pelvic and ureteral posterior walls were anastomosed first with 4-0 Vicryl (Johnson \& Johnson Inc, New Brunswick, NJ), a 6F double-J stent was inserted, and the ureter was sutured intermittently. In the anterior wall, the redundant pelvis was closed with continuous suture by 4-0 Vicryl, a drainage tube was placed, the lateral peritoneum was closed, and the operation was completed.

\section{Data collection and follow-up}

The patient's medical records, including the operation time, time required to manage the vessels during the operation, estimated blood loss during the operation, drainage tube removal time after the operation, hospital stay time, and postoperative complications were collected. Due to the economic factors and China's medical insurance policy, not all patients can afford the cost of diuretic renal dynamic imaging. Therefore, the success criteria of these patients are complete clinical relief of abdominal pain and improvement of hydronephrosis by B-ultrasound. If the patient's pain is not relieved or B ultrasound still indicates that hydronephrosis is not improved, it means that the surgery failed. During surgery, all patients underwent insertion of double J stent, which was removed approximately 8 weeks after the surgery. The improvement of the hydronephrosis before and 3 months after the operation was evaluated by abdominal B-ultrasound. All patients were followed up for more than 6 months, and changes in renal size were recorded before and 6 months after the operation.

\section{Statistical analysis}

SPSS (version 13.0) software (SPSS, Inc., Chicago, IL) was used for data analysis. Student' s t-test was used to compare the numerical variables; Fisher's exact test was used to compare the classified variables. $P$ values $<0.05$ were considered statistically significant.

\section{Results}

All of the patients underwent successful preservation of the crossing vessels and none of them were severed during the operation. There were 5 cases of mild hydronephrosis, 15 cases of moderate hydronephrosis, and 13 cases of severe hydronephrosis (Table 1). In this group, 24 patients were confirmed to have crossing vessel compression by preoperative imaging diagnosis, and an additional 9 patients were found to have crossing vessels during the operation. Among them, 29 cases exhibited heterotopic arteries and 4 cases were accompanied by heterotopic arteries and veins. The average operation time was $210.6 \pm 58.9 \mathrm{~min}$ in the whole

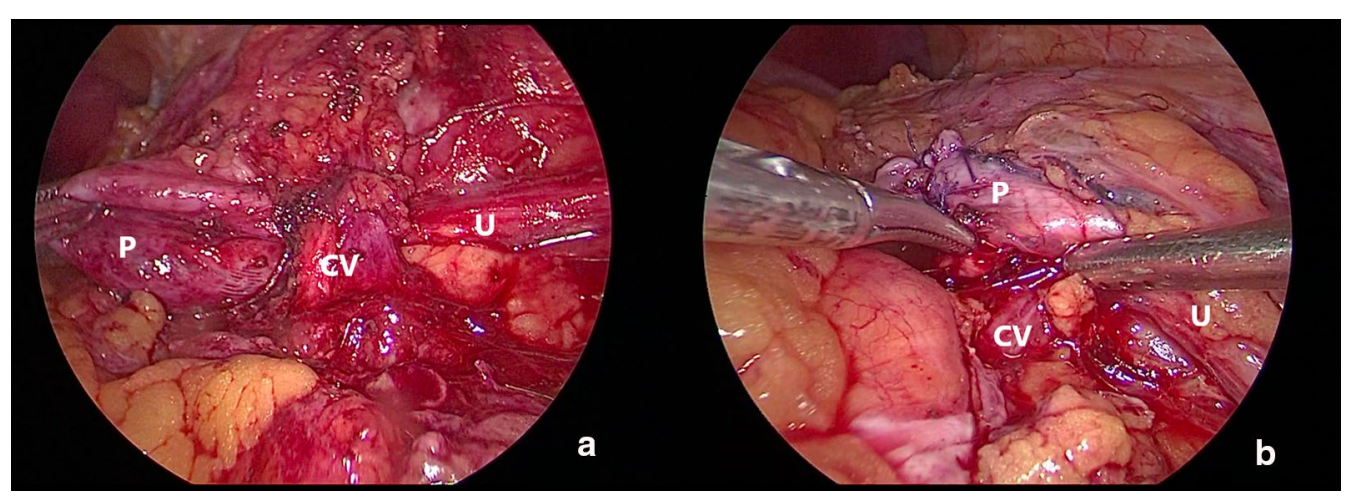

Fig. 2 Crossing vessel transposition, a before $L P, \mathbf{b}$ after $L P$ 
Table 1 Characteristics of patients and degree of hydronephrosis

\begin{tabular}{|c|c|c|c|c|}
\hline Items & Suspension team $(n=21)$ & Transposition team $(n=12)$ & Total $(n=33)$ & $P$ value \\
\hline Age (years), $\bar{x} \pm s$ & $33.5 \pm 13.4$ & $31.9 \pm 11.1$ & $32.9 \pm 12.2$ & 0.513 \\
\hline Male/Female, n & $14 / 7$ & $7 / 5$ & $21 / 12$ & 0.222 \\
\hline Side (left/right), $n$ & $12 / 9$ & $8 / 4$ & $20 / 13$ & 0.281 \\
\hline \multicolumn{5}{|c|}{ Degree of hydronephrosis } \\
\hline Mild, n (\%) & $3(14.3)$ & $2(16.7)$ & $5(15.2)$ & 0.29 \\
\hline Moderate, n (\%) & $9(42.9)$ & $6(50.0)$ & $15(45.5)$ & \\
\hline Severe, $\mathrm{n}(\%)$ & $9(42.9)$ & $4(33.3)$ & $13(39.4)$ & \\
\hline
\end{tabular}

group, $203.8 \pm 61.8 \mathrm{~min}$ in the suspension group, and $222.5 \pm 56.8 \mathrm{~min}$ in the transposition group. The mean treatment time of crossing vessels was $8.0 \pm 3.5 \mathrm{~min}$, that of suspension group was $5.9 \pm 1.4 \mathrm{~min}$, and that of the transposition group was $11.7 \pm 3.0 \mathrm{~min}$. The average volume of blood loss was $55.8 \pm 25.6 \mathrm{~mL}$. The average time of drainage tube removal was $4.6 \pm 2.0$ days and the average hospital stay was $11.4 \pm 3.0$ days (Table 2). In the transposition group, 1 patient exhibited slight urinary leakage and the drainage tube remained until the 9th day after the operation. The pathology of the stenosis of UPJ in all patients was chronic inflammation.

The hydronephrosis before and 3 months after the surgery were compared using abdominal B ultrasound as the standard to evaluate the effectiveness of the operation. There was a significant difference $(\mathrm{P}<0.05)$ observed in the entire group, wherein the average hydronephrosis was $4.8 \pm 1.5 \mathrm{~cm}$ before the operation and $1.2 \pm 1.3 \mathrm{~cm} 3$ months after the operation. Among them, the average hydronephrosis of the suspension group was $1.8 \pm 1.0 \mathrm{~cm} 3$ months after the operation, and that of the transposition group was $2.0 \pm 1.8 \mathrm{~cm}$ 3 months after the operation. There was no significant difference in the degree of pyelocele between the two groups $(P=0.269)$.

The changes in renal length before and 6 months after the operation were compared by abdominal B-ultrasound as an indirect index to evaluate whether the crossing vessels were effectively preserved. There was no significant difference between the two groups $(P>0.05)$. All patients were followed up until February 2020, with an average follow-up of 17 months, ranging from 6 to 28 months. The size of the kidneys in all patients had no significant change compared with that before operation and hydronephrosis was relieved.

\section{Discussion}

Crossing vessel compression is one of the common causes of UPJO, mostly related to congenital development. UPJO caused by crossing vessel compression accounts for $10-28.1 \%$ of adult primary UPJO $[1,2]$. The majority of the symptoms were pain or discomfort on the affected side of the waist and some patients were treated for hydronephrosis upon routine physical examination. Ectopic renal vessels (also known as renal vagal vessels) are mainly divided into ectopic renal arteries and ectopic renal veins (ectopic arteries are more common), which are usually located on the ventral side of the ureteropelvic

Table 2 Pre-operative-, intra-operative-, postoperative-, and follow-up- data of the two groups

\begin{tabular}{|c|c|c|c|c|}
\hline Items & $\begin{array}{l}\text { Suspension team } \\
(n=21)\end{array}$ & $\begin{array}{l}\text { Transposition team } \\
(n=12)\end{array}$ & Total $(n=33)$ & $P$ value \\
\hline Operative time/min & $203.8 \pm 61.8$ & $222.5 \pm 56.8$ & $210.6 \pm 58.9$ & 0.798 \\
\hline Crossing vascular management time/min & $5.9 \pm 1.4$ & $11.7 \pm 3.0$ & $8.0 \pm 3.5$ & 0.004 \\
\hline Blood loss/ml & $45.2 \pm 36.0$ & $74.2 \pm 85.3$ & $55.8 \pm 58.4$ & 0.182 \\
\hline Drainage time/d & $4.3 \pm 1.2$ & $4.8 \pm 2.4$ & $4.6 \pm 2.0$ & 0.495 \\
\hline Hospitalization time /d & $11.3 \pm 2.1$ & $11.4 \pm 3.7$ & $11.4 \pm 3.0$ & 0.967 \\
\hline Pre-operative hydronephrosis/cm & $5.0 \pm 1.6$ & $4.6 \pm 1.6$ & $4.8 \pm 1.5$ & 0.487 \\
\hline Post-operative hydronephrosis/cm & $1.8 \pm 1.0$ & $2.0 \pm 1.8$ & $1.2 \pm 1.3^{*}$ & 0.269 \\
\hline Pre-operative length of kidney/cm & $11.5 \pm 1.3$ & $11.4 \pm 1.2$ & $11.4 \pm 1.8$ & 0.720 \\
\hline Post-operative length of kidney/cm & $11.2 \pm 1.1$ & $11.7 \pm 1.3$ & $11.5 \pm 1.2 \#$ & 0.291 \\
\hline
\end{tabular}

${ }^{*}$ Compared with preoperative hydronephrosis $(P<0.05)$, \#Compared with preoperative renal length, $P>0.05$ 
junction and do not enter the kidney through the renal hilum. Additionally, some of them directly enter the lower pole of the kidney, with an incidence of about $6.3 \%$ [1].

There are different surgical methods for the treatment of crossing vessels. Hellström et al. [9] proposed an operation method for a vascular hitch (Hellström operation) as early as 1949 , which is considered the classic operation to deal with UPJO caused by crossing vessel compression. At present, Pesce et al. $[10,11]$ is known to still recommend the Hellström operation by laparoscopy for UPJO with crossing vessels. It is presumed that the operation is relatively simple; on the other hand, it can decide whether to further perform pyeloplasty according to the severity of the obstruction. Also, the advantage of LP is that it can obtain better esthetic outcome (the smaller scar) than that of OP [12]. Zhang [13] reported that eight cases of UPJO with crossing vessels underwent Hellström operation by retroperitoneal laparoscopy, all of which were successful. Based on fully dissecting the crossing vessels in the upper ureter and obstruction, the crossing vessels were embedded with 4-0 absorbable sutures and fixed on the anterior wall of the renal pelvis. This operation method ensured the blood supply to the kidney and completely resolved the problem of external compression of the ureteropelvic junction. Notably, indications need to be strictly observed.

Other authors have used the method of vascular transposition to deal with UPJO with crossing vessels. Boylu et al. [14] reported that 48 cases of UPJO with crossing vessels underwent laparoscopic pyeloplasty with robot assistance, of which 18 cases were successfully transposed. According to the author's opinion, it is necessary to judge whether crossing vessels cause actual compression to the pelvic canal according to the condition during the operation. Villemagne found that furosemide challenge test is a feasible method to determine whether there is UPJO during operation [15].

Pesce [10] arrived at a conclusion regarding the method of how to judge whether a crossing vessel is the direct cause of UPJO. He observed the effective peristalsis of UPJ and the rapid passage of urine from the renal pelvis by a diuretic test in 111 patients during the operation and judged whether to perform the Hellström operation. The report stated that the success rate of this method is $98 \%$ and only one patient received suspension of operation with a poor effect. It is worth noting that crossing vascular compression is not the only factor that causes UPJO. It is equally important to resect the obstructed part of the UPJ and reconstruct the junction. In most cases, ureteral stenosis or decreased peristalsis function occurs in the compression segment. Even if the external compression is relieved, dynamic obstruction still occurs in the ureter.
The data from Ellerkamp's study showed that there was no significant difference in the pathological characteristics of ureteral smooth muscle fibrosis, muscle hypertrophy, and inflammation between the UPJO patients with and without vascular compression.

Taken together, we suggest that the treatment of crossing vessels should be determined according to the position and direction of the ectopic vessels. In short, when the crossing vessels are close to the renal hilus (above the level of the lower pole midline of the kidney), the method of blood vessel suspension can be adopted (Fig. 1). When the crossing vessels are at the level of the lower pole of the kidney (below the level of the lower pole midline of the kidney), the method of crossing vessel transposition can be adopted (Fig. 2).

The average time of the crossing vessels management was $5.9 \pm 1.4 \mathrm{~min}$ in the suspension group and $11.7 \pm 3.0 \mathrm{~min}$ in the transposition group $(P<0.05)$. This is because the crossing vessels in the transposition group directly enter the lower pole of the kidney and the vessels are relatively short; therefore, they need to be completely free from the root of the lower pole of the kidney to the starting part. Subsequently, they should be fixed on the fascia of the psoas major muscle above the anastomosis with suture.

The obvious limitation of our study is the small number of patients. Furthermore, we know that there are several factors that can affect the final outcome of pyeloplasty: methods, approaches, techniques, as well as the manner of suturing and stenting. In addition, retrospective studies inevitably lead to case selection bias. In order to reduce the bias of the two groups of patients, only the patients who underwent laparoscopic pyeloplasty by the same surgeon were chosen.

In conclusion, the method of Hem-o-lok clips suspension or vascular transposition can be used to relieve the crossing vascular compression for UPJO patients with crossing vessel compression at the same time of pyeloplasty, according to the location and direction of the ectopic vascular, so as to further improve the success rate of pyeloplasty. It is simple and reliable to use Hem-o-lok clips to suspend ectopic blood vessels, which has a certain value in clinical applications.

\section{Abbreviations \\ UPJ: Ureteropelvic junction; UPJO: Ureteropelvic junction obstruction; LP: Laparoscopic pyeloplasty; CT: Computed tomography; CTU: Computed tomography urography. \\ Acknowledgements \\ Not applicable. \\ Authors' contributions \\ J.L and JJ.Z: project development, data analysis, manuscript writing. XJ.Y: project development, manuscript editing, operation performance. WN.C:}


project development, data collection. LL.X and XB.H: project development, manuscript editing. All authors read and approved the final manuscript.

\section{Funding}

This work was supported by the National Natural Science Foundation of China (Grant Nos. 62076007 to XJ.Y.).

\section{Availability of data and materials}

The datasets used and analyzed during the current study are available from the corresponding author on reasonable request.

\section{Declarations}

\section{Ethics approval and consent to participate}

The study was conducted in accordance with the Declaration of Helsinki (as revised in 2013). The study was approved by the ethics board of Peking University People's Hospital Review Board (2020PHB 125-01) and all patients signed the preoperative informed consent.

\section{Consent for publication}

Written informed consents for publication of their clinical details and images were obtained from the patients and are available for review by the Editor of this journal.

\section{Competing interest}

Jun Liu: No competing financial interests exist. Jingjun Zhang: No competing financial interests exist. Weinan Chen: No competing financial interests exist. Liulin Xiong: No competing financial interests exist. Xiaobo Huang: No competing financial interests exist. Xiongjun Ye: No competing financial interests exist.

\section{Author details}

${ }^{1}$ Urology and Lithotripsy Center, Peking University People's Hospital, Peking University, 133 Fuchengmen Inner Street, Xicheng District, Beijing 100034, People's Republic of China. ${ }^{2}$ Peking University Applied Lithotripsy Institute, Peking University, Beijing 100034, China. ${ }^{3}$ Department of Urology, Peking University BinHai Hospital (Fifth Tianjin Central Hospital), Tianjin 300450, China.

Received: 7 January 2021 Accepted: 26 March 2021

Published online: 06 May 2021

\section{References}

1. Ellerkamp V, Kurth RR, Schmid E, et al. Differences between intrinsic and extrinsic ureteropelvic junction obstruction related to crossing vessels: histology and functional analyses. World J Urol. 2016;34(4):577-83.
2. Zhang X, Li HZ, Wang SG, et al. Retroperitoneal laparoscopic dismembered pyeloplasty: experience with 50 cases. Urology. 2005;66:514-7.

3. Szavay P, Heyne-Pietschmann M, Zundel SM. Uretero-pelvic junction obstruction due to crossing pole vessel: contra vascular hitch. Aktuelle Urol. 2020;51(2):121-6.

4. Polok M, Toczewski K, Borselle D, Apoznański W, Jędrzejuk D, Patkowski D. Hydronephrosis in children caused by lower pole crossing vessels-how to choose the proper method of treatment? Front Pediatr. 2019;7:83.

5. Chiarenza SF, Bleve C, Caione P, et al. Minimally invasive treatment of pediatric extrinsic ureteropelvic junction obstruction by crossing polar vessels: is vascular hitching a definitive solution? Report of a multicenter survey. J Laparoendosc Adv Surg Tech A. 2017;27(9):965-71.

6. Uhlig A, Uhlig J, Trojan L, et al. Surgical approaches for treatment of ureteropelvic junction obstruction-a systematic review and network meta-analysis. BMC Urol. 2019;19(1):112.

7. Hashim H, Christopher RJ. Ureteropelvic junction obstruction. Eur Urol Suppl. 2012;11:25-32.

8. Ellenbogen P, Scheible F, Talner L, et al. Sensitivity of gray scale ultrasound in detecting urinary tract obstruction. AJR Am J Roentgenol. 1978;130(4):731-3.

9. Hellström J, Giertz G, Lindblom K. Pathogenesis and treatment of hydronephrosis. J Belge Urol. 1951;20(1):1-6.

10. Pesce C, Campobasso P, Costa L, Battaglino F, Musi L. Ureterovascular hydronephrosis in children: is pyeloplasty always necessary? Eur Urol. 1999:36(1):71-4.

11. Sakoda A, Cherian A, Mushtaq I. Laparoscopic transposition of lower pole crossing vessels ('vascular hitch') in pure extrinsic pelvi-ureteric junction (PUJ) obstruction in children. BJU Int. 2011;108(8):1364-8.

12. Masieri L, Sforza S, Cini C, et al. Minilaparoscopic versus open pyeloplasty in children less than 1 year. J Laparoendosc Adv Surg Tech A. 2019;29(7):970-5.

13. Zhang X, Xu K, Fu B, et al. The retroperitoneal laparoscopic Hellström technique for pelvi-ureteric junction obstruction from a crossing vessel. BJU Int. 2007;100(6):1335-8.

14. Boylu U, Oommen M, Lee BR, et al. Ureteropelvic junction obstruction secondary to crossing vessels-to transpose or not? Robot Exp J Urol. 2009;181(4):1751-5.

15. Villemagne T, Fourcade L, Camby C, et al. Long-term results with the laparoscopic transposition of renal lower pole crossing vessels. J Pediatr Urol. 2015;11(4):174.e1-174.e1747.

\section{Publisher's Note}

Springer Nature remains neutral with regard to jurisdictional claims in published maps and institutional affiliations.

Ready to submit your research? Choose BMC and benefit from:

- fast, convenient online submission

- thorough peer review by experienced researchers in your field

- rapid publication on acceptance

- support for research data, including large and complex data types

- gold Open Access which fosters wider collaboration and increased citations

- maximum visibility for your research: over $100 \mathrm{M}$ website views per year

At BMC, research is always in progress.

Learn more biomedcentral.com/submissions 